\title{
Smart Home Energy Management System Design: A Realistic Autonomous V2H / H2V Hybrid Energy Storage System
}

\author{
Bassam Zafar ${ }^{1}$ \\ Information System Department, FCIT \\ King Abdulaziz University, Jeddah \\ Saudi Arabia \\ Ben Slama Sami \\ Jeddah Community college, JCC \\ King Abdulaziz University, Jeddah \\ Saudi Arabia
}

\author{
Sihem Nasri ${ }^{3}$ \\ Department of Physics, \\ Analysis and Treatment of Electrical and Energy Systems \\ Unit, Faculty of Sciences of Tunis Tunisia
}

\author{
Marwan Mahmoud ${ }^{4}$ \\ Jeddah Community college, JCC \\ King Abdulaziz University, Jeddah \\ Saudi Arabia
}

\begin{abstract}
The hybrid fuel cell electric vehicle powered by household power during peak use is another opportunity to reduce emissions and save money. For this reason, Vehicle-toHome (V2H) and Home-to-Vehicle (H2V) systems were proposed as a new method of exchanging smart energy and a new method of exchanging smart energy. The main goal of this paper is to develop a smart home energy management based on IoT, generate more energy efficiency and share production between home and vehicle. In fact, the Hybrid Fuel cell electric vehicle will be used simultaneously to power household appliances during peak demand for electricity to solve energy consumption. The household's energy is derived from an accurate Autonomous hybrid power system. Several technologies such as Proton Exchange Membrane Fuel Cell, solar panel, Supercapacitor (SC) device and water electrolyzer are incorporated into the proposed system. Two-way electrical energy from the PEMFC-Hybrid Electric Vehicle and household power will be exchanged by discharging vehicle energy storage to balance energy demand and supply. To this end, a smart energy management unit (EMU) will be developed and discussed in order to meet the estimated fuel consumption mitigation goals during peak periods when demand is highest, coordinating between household power and vehicle energy storage. The Matlab / Simulink software based on an experimental database extracted from household power to demonstrate the effectiveness of the proposed strategy and its effects on V2H / $\mathrm{H2V}$ operations will simulate the presented design for one day. The Matlab / Simulink software based on an experimental database extracted from household power to demonstrate the effectiveness of the proposed strategy and its effects on $\mathrm{V} 2 \mathrm{H} / \mathrm{H} 2 \mathrm{~V}$ operations will simulate the presented design for one day.
\end{abstract}

Keywords-Home energy management system; fuel cell; supercapacitor; solar power; vehicle to home; home to vehicle

\section{INTRODUCTION}

\section{A. Motivations}

The rapid development of a new economic hybrid electric vehicle and renewable energy, including solar photovoltaic and wind energy, has enhanced energy demand and environmental crises [1-2]. Hybrid Fuel Cell Electric vehicles have been selected as an attractive potential for reducing demand for oil, emissions and becoming a grid-capable electric vehicle (loading and/or discharging via grid or home). Indeed, to replace conventional ICE vehicles, these new generations of electric vehicles (EVs) have been developed. The household power has attracted a lot of attention in both academia and industry, according to the rapid evolution of clean energy production and the new economic EVs [3-4]. Different home energy management systems (HEMS) were designed and developed to control household fuel consumption power during peak periods. The HEMS was used as tools for sharing and reducing energy demand based on energy consumption and home profiles of production. In general, HEMS creates optimal schedules for consumption and production through multiple goals such as load profiles, energy demand and costs [5]. EVs are seen as attractive sources for household power during peak consumption using newly introduced HEMS technologies. In a sophisticated home energy system, various projects on the smart home have considered $\mathrm{H} 2 \mathrm{~V}$ and $\mathrm{V} 2 \mathrm{H}$ a novelty. The $\mathrm{V} 2 \mathrm{H}$ was described as an energy storage system in which the EV was used during peak periods when demand is highest to provide the home with electricity. Besides renewable energy sources such as solar energy, wind turbines, etc., it is also possible to consider vehicles as an energy source to meet the home energy demand [6]. Besides renewable energy sources such as solar energy, wind turbines, etc., it is also possible to consider vehicles as an energy source to meet the home energy demand [7]. Moreover, several methods and platforms, such as Intelligent Sensor Technologies, Home Network, and Smart Home Appliance [8-9], have been studied and developed for the smart home. Furthermore, due to the complexity and diversity of systems, as well as repeated control strategies without the problem of optimum level, the full potential of smart homes is still present. The purpose of intelligent home energy management was to control application and data acquisition, 
production, transmission, and network electricity [10]. Moreover, this smart management has attracted more interest from the research community to use a modern automation technology in the smart house promises. In order to share energy demand, performance and an intelligent network economy, it is essential to reconcile EVs and renewable energy to optimize the energy balance. As a result, researchers recently focused on developing advanced platforms for smart energy management to integrate electric vehicles and renewable energies into household and grid loads, as well as new materials and renewable energy structure considering the efficiency of power conversion [11].

Several works with Home-to-Vehicle and Vehicle-toHome Technologies have been presented in the literature. Several platforms have been put in place and tested. The designed systems were reviewed to demonstrate that the energy supplied to the electric charge is sufficient depending on the demand or load power. During peak consumption, different scenarios were added to control the household power to share the required energy. Different methods and techniques have been used as mathematical optimization to create an efficient hour of operation, accurate production decisions and good consumption.

The rest of this article will be organized as follows: Home Energy Management System (HEMS); (HEMS) System Design; the energy management section will explain the proposed smart and the concluding remarks will be discussed in the conclusion and future work section.

\section{B. Summary of Home Energy Management System (HEMS) using the Smart Home (Home Automation)}

The developed HEMS were selected as a new energy management approach to ensure energy savings and peak demand [12]-[13]. Broadly speaking, HEMS can be defined as a precise approach system that allows households to control their energy demand by adding various network-wide hardware / software connections [14]. HEMS were also taken in various forms, for example:

- HEMS can provide consumers with information on how to use energy at home and/or provide incentives for cha nging consumption [15].

- HEMS can provide the ability of the household to control energy processes consumed at home through a smart phone or Web service. Home Appliances can be managed or implemented either manually using rule sets that can be planned or optimized based on the behavior of the user [16].

HEMS has emerged as an effective control of household appliances which, on the one hand, can provide power and, on the other, reduce peak loads. Using the most relevant technologies, energy savings and demand savings can be grouped into four categories: home automation, integrated wireless technology, smart home micro-computers, and home energy management system.

The Internet of Things (IoT) was selected to communicate between appliances. Communication can be enabled to the remote devices via selected interfaces such as gateways.
Several projects have been developed in this context (such as: Baywatch, Fiemser, Smart House / Smart Grid, etc...) to meet the needs of consumers or industrialists.

Making smart homes, simplifying household life, ensuring home security and maximizing occupant comfort with minimal energy use are the main goals for developing these projects.

\section{Summary of IoT-Based Smart Home Automation System}

Because of its various interests, wireless sensor networks (WSN) are selected as an attractive potential. The WSNs aim to offer several advantages over traditional approaches for different new applications such as: environmental monitoring; health security; smart homes, etc. [17]. The Internet protocol (IPv4 or IPV6) was used as an accurate solution to develop the Internet of Things (IoT) to connect appliances [18]. WSN therefore faces many obstacles that include different challenges such as:

- How to use a small and low power node effectively?

- How to implement the security required when data is transmitted between nodes?

- How to solve environmental conditions when transmitti ng data?

Several studies conducted WSN with IP to develop IoT without interruption to ensure real-time connectivity between different nodes. For example, the author proposed and developed a precise IoT-based WSN platform in [19]. The WSN-Platform developed is aimed at collecting the data detected in real time [20]. The results obtained were demonstrated based on low power consumed by each node. In, the authors proposed a WSN framework for controlling smart home appliance devices requiring energy. According to a given experimental database, the proposed platform deals with monitoring and control of house equipment [21]-[22]. The WSNs were shared data via an internet connection to ensure real - time connectivity between appliances.

\section{The Problematic}

The emergence of sophisticated electrical systems and high popular inflation strengthened rising electricity demand. Therefore, today the world faces a major challenge in finding a radical solution to the problem of energy deficit that stems mainly from the imbalance in demand-production. Indeed, the power grid is facing the balance that maintains the issue of climate change-influenced peak management of demand and supply and demand. In addition, ancient housing technology supported heavy energy consumption. The house is therefore seen as a complex node of energy linked to many energy flows.

The imminent integration of renewable sources and electric vehicles will strengthen this node and exacerbate the management problem that rests on monitoring and optimizing all these flows to enable proper distribution of energy to household equipment. Electricity users are also faced with costly tariffs on energy caused by massive energy consumption and unlimited user demand. 


\section{E. Contributions}

The principle commitment anticipated from this work is to build up a savvy home administration exploiting Home-toVehicle (H2V) and Vehicle-to-Home (V2H) innovation techniques with a smart supervision control methodology so as to achieve a few upgrades:

- Ensure the storage process in positive conditions.

- Energy request fulfillment whatever the conditions: stand up to fuel and energy needs.

- Vehicle fuel charging from home mulling over the energy request.

- System elements security:

- Avoid the Supercapacitor cheating and overproduction of $\mathrm{H}_{2}$ gas fuel

$\circ \mathrm{Be}$ confronting profound Supercapacitor release and overwhelming fuel utilization.

\section{SySTEM DESIGN}

The given system aims to maintain the power balance between demand and production considering the energy storage and recovery phenomenon and the control of the energy flows transferred between the vehicle and the house. Hence, the described system deals with several main duties:

- Home production and demand control.

- Vehicle demand control and charging.

- Fuel distribution way control.

Thus, the two-way energy exchange phenomena insured by the vehicle and the smart home is highlighted. Indeed, the given system is operated according to two modes depending on the distribution way nature. These two modes are provided by set of energy equipments as PV source, Electrolyzer, Supercapacitor and Fuel Cell.

The first distribution way is ensured from the house to the parked vehicle "H2V". Indeed, in case of excess energy, the system uses the amount of hydrogen generated at home to electrify the vehicle after checking its lack and storage capacity. While there is need of energy in the house, the second distribution way is highlighted. In this case the house production equipment are unable to meet the energy needs, which requires the use of the car reserve to remedy the energy shortage "V2H" (see Fig.1). The system therefore requires an intelligent control unit for distribution and consumption in order to ensure the system's ideal functioning and protect it against any constraint that may lead to its corruption.

- The energy production: This constitutes the energy issued from the photovoltaic module located at the house roof. the expression of the PV generated current is described as [23]:

$I_{P V}=I_{p h}-I_{s} e^{\left(\frac{N_{S} \cdot V_{P V}+N_{P} \cdot I_{P V} \cdot R_{s}}{V_{T}}\right)}-\frac{N_{S} \cdot V_{P V}+N_{P} \cdot I_{P V} \cdot R_{s}}{R_{s h}}$
- The energy consumption: It is defined by the total installed appliances consumption. this energy may be used for lighting, heating, leisure,

$I_{L D}=\sum_{i=0}^{n} I_{A P_{i}}$

- Electrolyzer equipment: It is an electrochemical device that, in the presence of an excess power current, produces hydrogen by decomposing the water molecule into $\mathrm{H}_{2}$ and $\mathrm{O}_{2}$ gas. The generated hydrogen flow is calculated from the Faraday law as [24]:

$Q_{P}=\frac{\eta_{E L_{F}} \cdot N_{E L} \cdot I_{E L}}{2 . F}$

- Supercapacitor equipment: It is an electrical device that through its discharge can accomplish the energy recovery process. So, to ensure its protection against the deep discharge, the Supercapacitor is controlled by its state of charge described by the expression [25]:

$S O C_{S C}=\left[\frac{I_{S C}}{I_{S C_{\max }}}\right]^{2}$

Instead of battery, Supercapacitor is used as a short term energy storage device which is intervening in a period when excess generated power is lower than that nominal of electrolyzer.

- $\mathbf{H}_{2}$ Station: It is equipment dedicated to the storage of the produced hydrogen flux. The storage process made under high pressure follows the law described by the equation below [26]:

$P_{s t}=\frac{R \cdot T_{s t}}{V_{s t}} \cdot Q^{S}$

The hydrogen flow storage control is made by state of charge verification that is expressed as:

$S O C_{H 2}=\frac{Q^{S}}{Q_{\max }^{S}}$

- Fuel Cell equipment: It is a generator which, in the presence of hydrogen, generates an electric current in order to assist in the load demand satisfaction. The hydrogen consumption is described according the Faraday law as [27]:

$Q_{C}=\frac{N_{F C} \cdot I_{F C}}{2 \cdot F \cdot \eta_{F C_{F}}}$

- Electric Vehicle: It is an electric vehicle based on fuel cell that requires hydrogen as fuel to be running. 


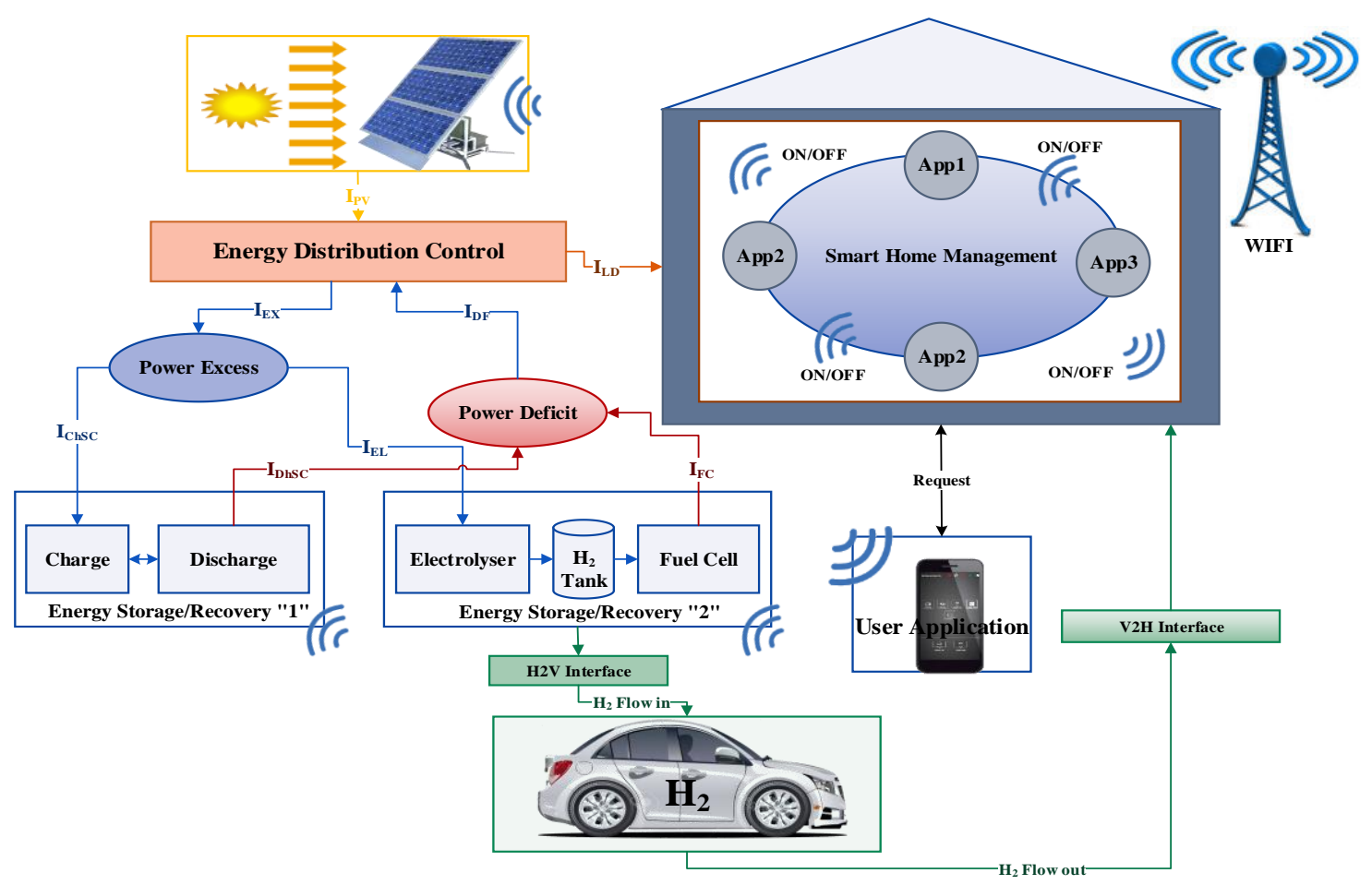

Fig. 1. Design of the Proposed Autonomous Hybrid System.

\section{Smart Management ApPROACH}

The reliability and the effectiveness of smart home management system are verified by its ability to manage quickly and intelligibly complex occurred constraints and fluctuations. Indeed, performance improvement of the studied system relies on the integration of a smart energy management approaches considering various criteria as:

- Energy distribution flows.

- Fuel flow generation and transfer.

- Energy consumption rates.

- Component state control and secure.

To study system reactions in front of happened events, two main parts can be highlighted:

- Excess power production management to protect storage devices against overcharge and full storage. This can be achieved by developing a smart approach control considering flow transfer from Home to Vehicle "H2V" (Fig. 2).

- Deficit power management to secure backup devices against massive fuel consumption and the deep discharge. Indeed, a smart approach control relying on fuel transfer from Vehicle to Home "V2H" is considered to compensate lacks (Fig. 3).

Thus, several control parameters must be highlighted to accomplish effective management processes as home energy consumption/production, fuel storage/use and charging/discharging of electrical device.

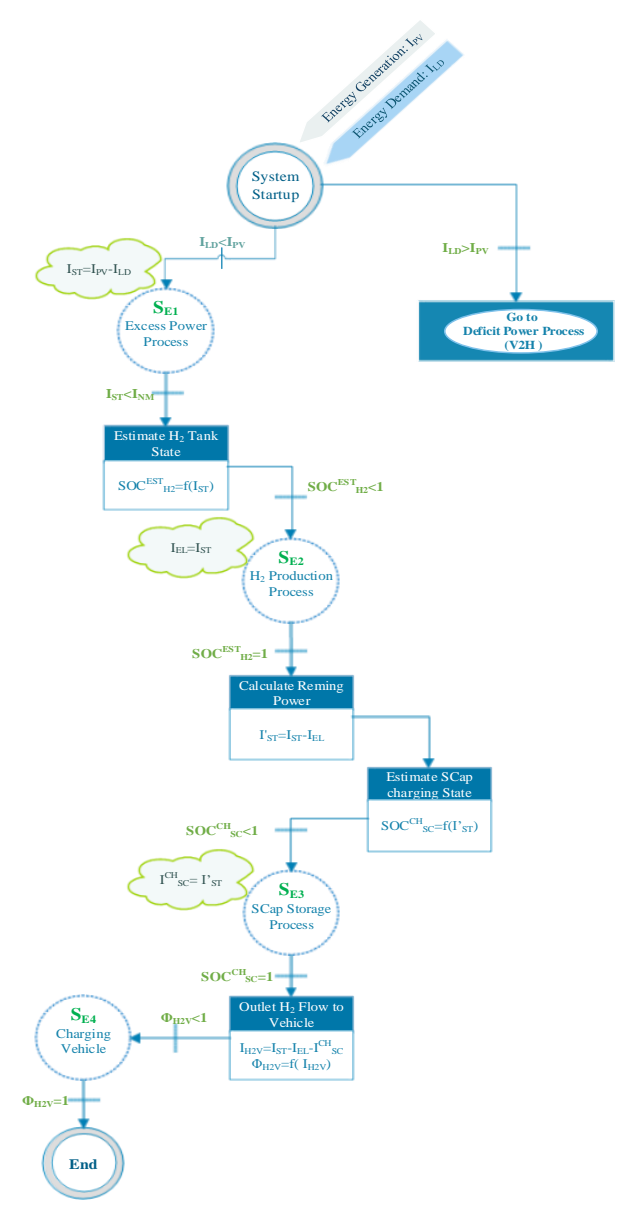

Fig. 2. Home-to Vehicle Energy Distribution Process. 


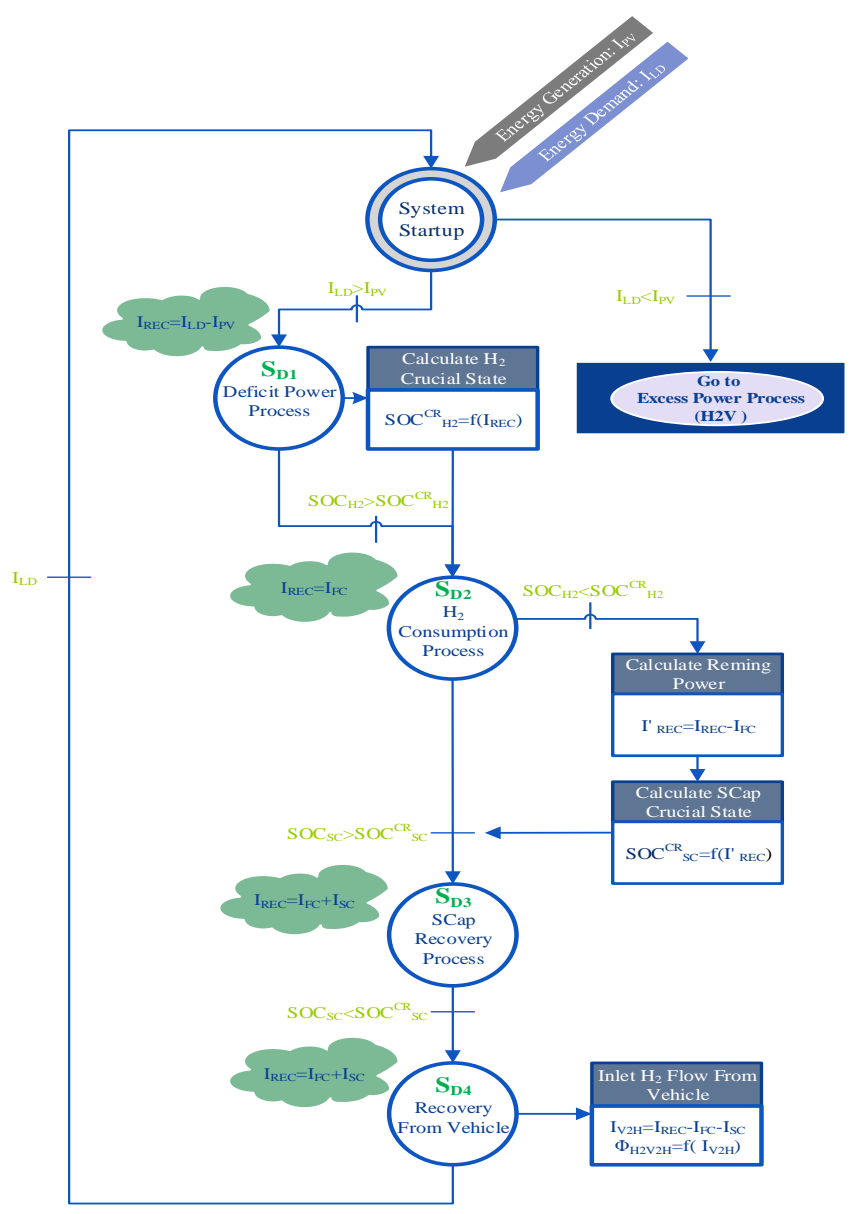

Fig. 3. Vehicle-to-Home Energy Distribution Process.

\section{FIndingS AND RESUltS}

\section{A. Home to Vehicle}

The obtained results have been carried out under the Matlab/Simulink environment to evaluate system performance and demonstrate its reliability against unforeseen events. In fact, experimental consumption profiles are restored to describe the electricity supplied to meet the required energy requirements for domestic devices in order to complete the simulation procedure. Solar energy is considered the main source to meet a continuous energy demand, according to the results obtained. The load profile is also comparable with the load on an intelligent home in the audiovisual environment. Solar energy is controlled by energy demand to determine the system status (excess/deficit) in comparison to energy consumption. The current profile also deals with the house's energy consumption for a period of (24 hours). Fig. 4 illustrates the balance of energy production and consumption. As seen, the system is located within different periods of excess, which will analyze and study the system reaction by referring to them (Fig. 5). The proposed strategy prove an efficient coordination between home and vehicle "H2V". The excess power generation is used to protect storage devices against overload and full storage. Thus, Fig. 6 shows the estimated relative hydrogen volumes and supercapacitor charging capacity respectively. Under satisfied conditions, $\left(\mathrm{I}_{\mathrm{EX}}>\mathrm{I}_{\mathrm{EN}}\right.$ and $\left.\mathrm{SOC}_{\mathrm{H} 2}<\mathrm{SOC}_{\mathrm{Max}}\right)$, the system permits the chemical storage $\left(\mathrm{H}_{2}\right.$ gas) process by sending an activation key to Electrolysis device. The system uses also the SuperCapacitor to manage crucial storage states caused by either full $\mathrm{H}_{2}$ tank or unsatisfied electrolysis operation condition. In addition, the possible fuel amounts production and the amounts to be delivered by the $\mathrm{H} 2 \mathrm{~V}$ system are depicted in Fig. 7. As noticed, once the house is over-energy marked, the surplus is transformed to bring the car. In this case, the car is fed by the house.

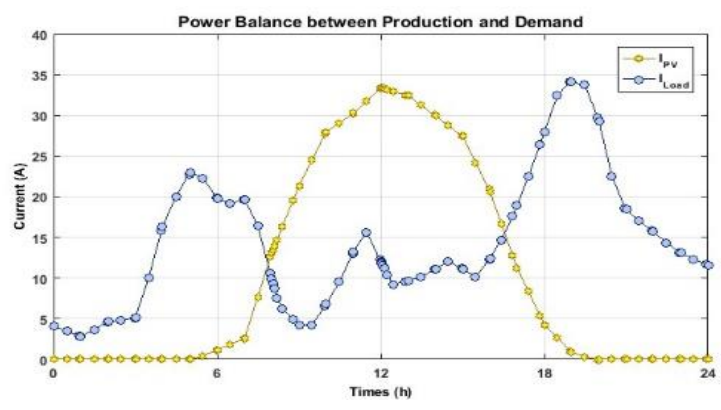

Fig. 4. Power Balance between Consumption and Production.
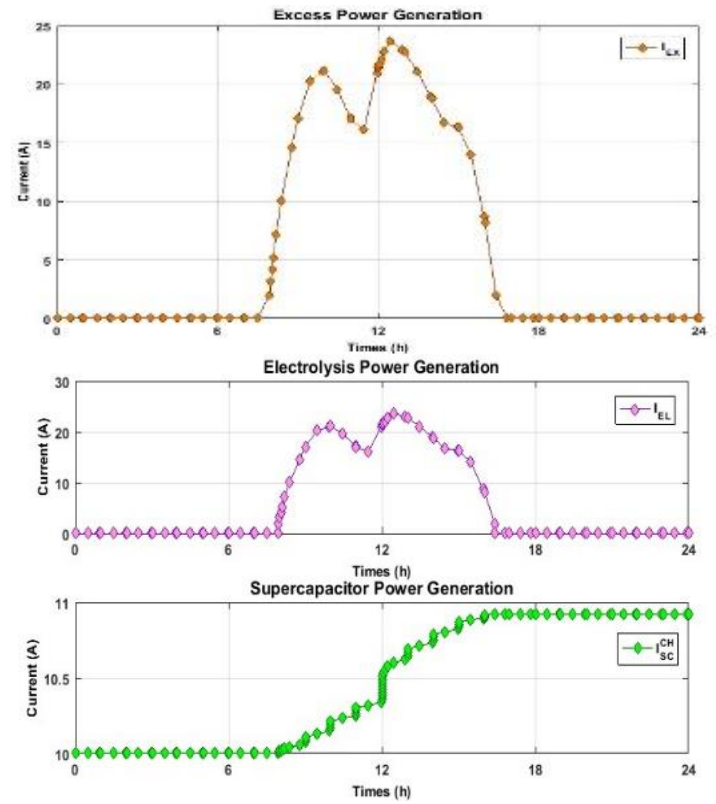

Fig. 5. Excess Power Generation for Storage Devices.
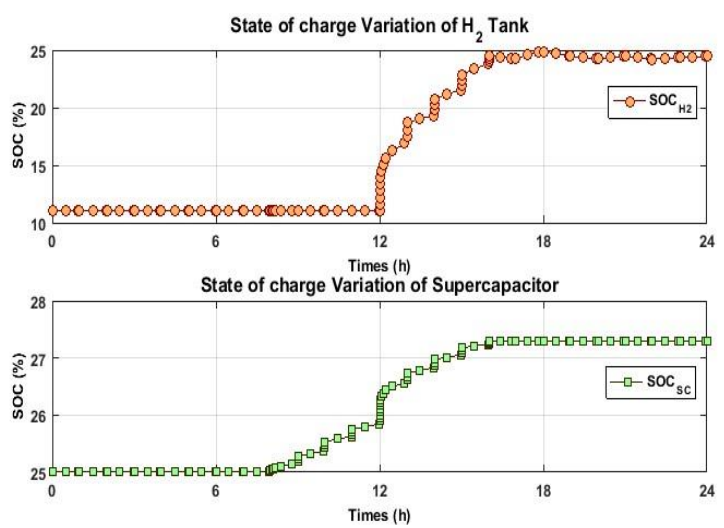

Fig. 6. Hydrogen and Super-Capacitor State of Charge Variations Over 24 hours. 

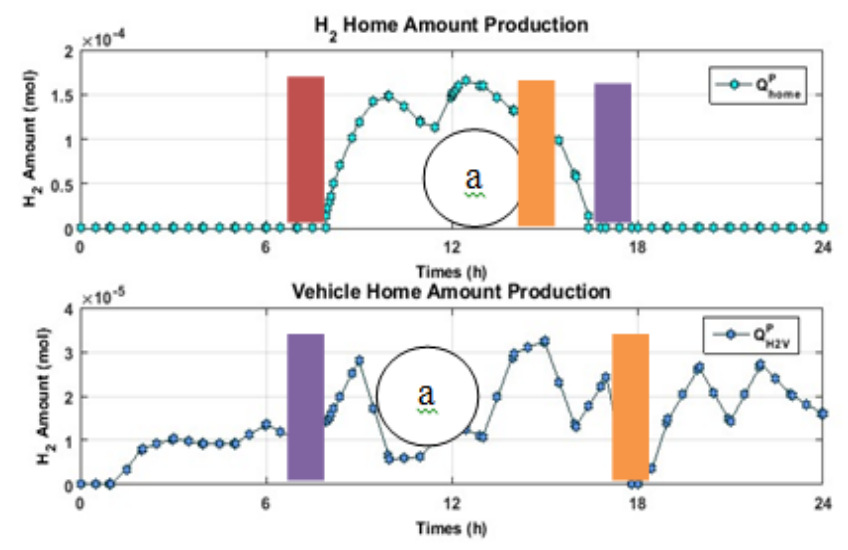

Fig. 7. Home-Vehicle Energy Variations.

\section{B. Vehicle to Home}

Due to the lack of hydrogen $\left(\mathrm{SOC}_{\mathrm{H} 2}=0\right)$, the fuel cell cannot be launched to meet energy demand for the first time in deficits. The system uses SCap to make up for the need. The fuel cell is activated during the second period (from 12h) to meet the requirements. Because of full hydrogen consumption and SCap discharge, it seems that the fuel cell and the SCap are located under their critical states (see Fig. 8).

The total amount of $\mathrm{H}_{2}$ fuel will be converted into electricity and then injected into a network to compensate for its problem of incapacity. When the system is complaining for a new deficit, it provides the $\mathrm{H}_{2}$ needed to correct the power shortage due to the inability of the Fuel Cell. Fig. 9 is used to describe hydrogen tank amount fluctuation phenomenon during deficit periods. We can therefore note that the SuperCapacitor was used in the deficit power case and when the storage tank is empty, which means that the fuel cell cannot supply the required energy. As a result, the charge status of the Super-capacitor, used in its discharge mode, decreases (50\%) from its original level. While in other cases, only $\mathrm{H}_{2}$ phenomena are underlined in gas production and consumption.

To compensate for deficiencies, the transfer of fuel from the vehicle to the "V2H" home is considered (see Fig.10).

The vehicle provides the necessary energy to the house when the tank is empty and the Super-Capacitor is unable to correct the fluctuation.

\section{Discussion}

Based on the scientific literature resources that deal with smart home technology, we noticed the originality of our work as it not only develops an intelligent control strategy but also it treats the possibility of integrating hydrogen vehicles as means to compensate the deficit on the one hand and to ensure the secure energy storage on the other hand. Thus, the two studied techniques $\mathrm{H} 2 \mathrm{~V}$ and $\mathrm{V} 2 \mathrm{H}$ are in fact a challenge for the development of smart home systems. In addition, this work investigates the communication between system elements to improve its performance especially its response time to be face any unwanted event. But it remains to implement these strategies on embedded target board and improve them by the integration of other techniques that serve to optimize certain system equipment.
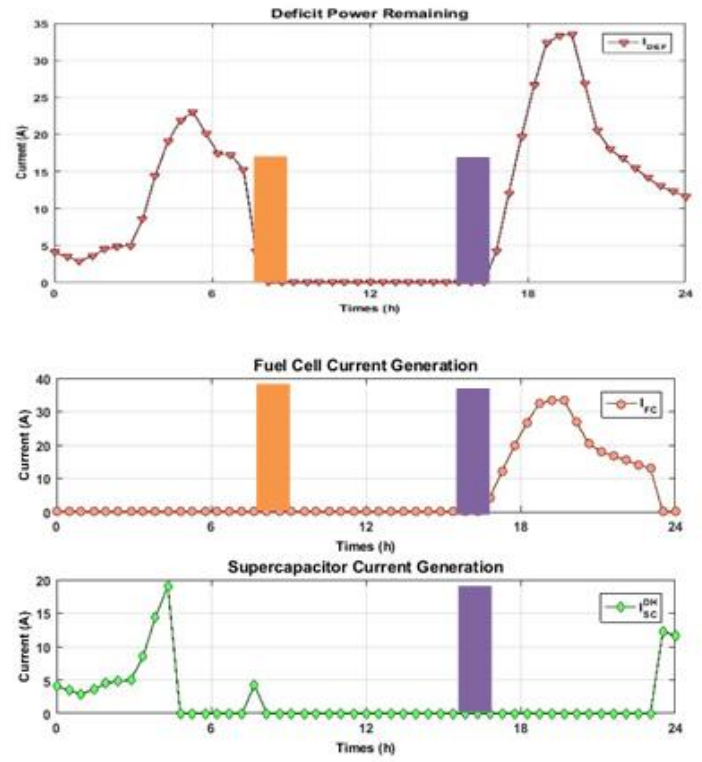

Fig. 8. Fuel Cell and Super-Capacitor Energy Variations Over Deficit Power.
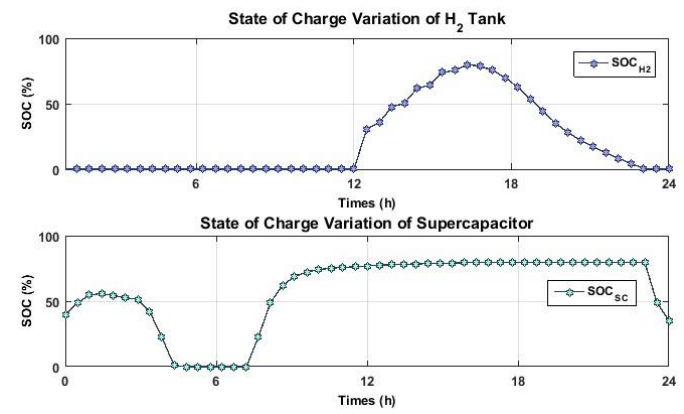

Fig. 9. Hydrogen Tank and Super-Capacitor State of Charge Variations.
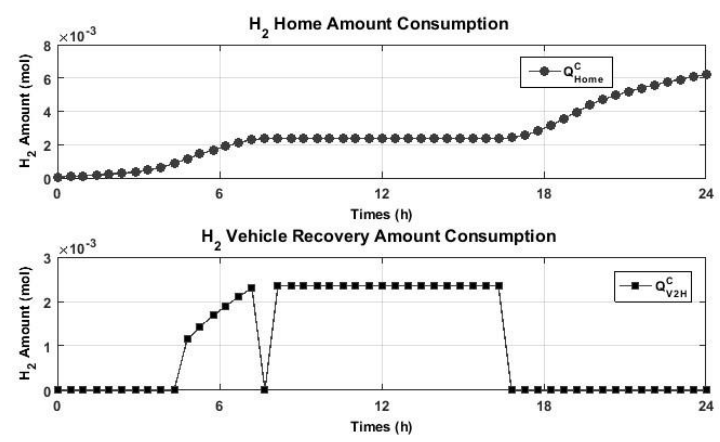

Fig. 10. Home-Vehicle Energy Variations.

\section{CONCLUSION}

An intelligent energy management approach is presented and described to manage the energy flows and to ensure power distribution. The proposed system is then made to test its performance with a Matlab / Simulink prototype. The obtained results show that the system is capable of handling changes and their effect on the operation of equipment.

As a future, we tend to develop the whole system based on vehicle charges by produced hydrogen (H2V/V2H) with an energy storage component (excess power case). 


\section{ACKNOWLEDGMENT}

The author would like to thank the Deanship of Scientific Research (DSR), King Abdulaziz University, and Jeddah, who supported this work under grant No. (G: 665-611-1439). The authors, therefore, gratefully acknowledge the DSR for their technical and financial support.

\section{REFERENCES}

[1] X. Su, P. Wolfs and M. Masoum, "Comprehensive optimal photovoltaic inverter control strategy in unbalanced three-phase four-wire low voltage distribution networks", IET Generation, Transmission \& Distribution, vol. 8, no. 11, pp. 1848-1859, 2014. Available: 10.1049/ietgtd.2013.0841.

[2] R. Liao and N. Yang, "Evaluation of voltage imbalance on low-voltage distribution networks considering delta-connected distribution transformers with a symmetrical NGS", IET Generation, Transmission \& Distribution, 2017. Available: 10.1049/iet-gtd.2017.0631.

[3] S. Zalzar, M. Shafiyi, A. Yousefi-Talouki and M. Ghazizadeh, "A smart charging algorithm for integration of EVs in providing primary reserve as manageable demand-side resources", International Transactions on Electrical Energy Systems, vol. 27, no. 4, p. e2283, 2016.

[4] K. Sudheer, K. Aravind kumar and P. Prasanna, "Fuzzy and PI Control of Hybrid Fuel Cell/Battery Distributed Generation Systems", International Journal of Modeling and Optimization, pp. 95100, 2011. Available: 10.7763/ijmo.2011.v1.17.

[5] H. Fathabadi, "Novel standalone hybrid solar/wind/fuel cell/battery power generation system", Energy, vol. 140, pp. 454-465, 2017. Available: 10.1016/j.energy.2017.08.098.

[6] P. S, "Hybrid Power Generation by Using Solar and Wind Energy Hybrid Power Generation Applicable To Future Electric Vehicle", International Journal of Emerging Trends in Science and Technology, vol. 4, no. 11, 2017. Available: 10.18535/ijetst/v4i11.01.

[7] B. Sami, N. Sihem, S. Gherairi and C. Adnane, "A Multi-Agent System for Smart Energy Management Devoted to Vehicle Applications: Realistic Dynamic Hybrid Electric System using Hydrogen as a Fuel", Energies,vol.12,no.3,p.474,2019.Available: 10.3390/en12030474.

[8] B. Sami, N. Sihem and Z. Bassam, "Design and implementation of an intelligent home energy management system: A realistic autonomous hybrid system using energy storage", International Journal of Hydrogen Energy, vol. 43, no. 42, pp. 19352-19365, 2018. Available: 10.1016/j.ijhydene.2018.09.001.

[9] A. Haddad, M. Ramadan, M. Khaled, H. Ramadan and M. Becherif, "Study of hybrid energy system coupling fuel cell, solar thermal system and photovoltaic cell", International Journal of Hydrogen Energy, 2018. Available: 10.1016/j.jhydene.2018.06.019.

[10] S. Sami, "Dynamic Modeling, and Simulation of Hybrid Solar Photovoltaic, and PEMFC Fuel Cell Power System", RA Journal of Applied Research, vol. 4, no. 5, 2018. Available: 10.31142/rajar/v4i5.02.

[11] S. Lim and G. Li, "An Integrated Home Energy Management System", Ponte International Scientific Researchs Journal, vol. 73, no. 12, 2017. Available: 10.21506/j.ponte.2017.12.53.

[12] E. Park, B. Hwang, K. Ko and D. Kim, "Consumer Acceptance Analysis of the Home Energy Management System", Sustainability, vol. 9, no. 12, p. 2351, 2017.

[13] R. Hemmati, "Technical and economic analysis of home energy management system incorporating small-scale wind turbine and battery energy storage system", Journal of Cleaner Production, vol. 159, pp. 106-118, 2017. Available: 10.1016/j.jclepro.2017.04.174.

[14] R. S. and M. V., "HEM algorithm based smart controller for home power management system", Energy and Buildings, vol. 131, pp. 184192, 2016. Available: 10.1016/j.enbuild.2016.09.026.

[15] B. Rao, F. Kupzog and M. Kozek, "Phase Balancing Home Energy Management System Using Model Predictive Control", Energies, vol. 11, no. 12, p. 3323, 2018. Available: 10.3390/en11123323.

[16] S. Pirbhulal et al., "A Novel Secure IoT-Based Smart Home Automation System Using a Wireless Sensor Network", Sensors, vol. 17, no. 12, p. 69, 2016. Available: 10.3390/s17010069.
[17] B. S.S. Tejesh and S. Neeraja, "A Smart Home Automation system using IoT and Open Source Hardware", International Journal of Engineering \& Technology, vol. 7, no. 27, p. 428, 2018. Available: 10.14419/ijet.v7i2.7.10856.

[18] R. Lakshmi, P. Karthika, A. Rajalakshmi and M. Sathya, "Smart-Home Automation Using IoT-Based Sensing and Monitoring Platform", International Journal of Scientific Research in Computer Science, Engineering and Information Technology, pp. 409-413, 2019. Available: $10.32628 /$ cseit 195190 .

[19] J. Kim, "HEMS (home energy management system) base on the IoT smart home", Contemporary Engineering Sciences, vol. 9, pp. 21-28, 2016. Available: 10.12988/ces.2016.512316.

[20] S. Pirbhulal et al., "A Novel Secure IoT-Based Smart Home Automation System Using a Wireless Sensor Network", Sensors, vol. 17, no. 12, p. 69, 2016. Available: 10.3390/s17010069.

[21] A. Eslami and T. Ghanbari, "New mathematical model from system standpoint to analyse and mitigate PV leakage current of large PV strings/arrays", IET Generation, Transmission \& Distribution, vol. 13, no. 4, pp. 543-552, 2019. Available: 10.1049/iet-gtd.2018.5030.

[22] H. Lee, K. Kim and Y. Kim, "Wireless Sensor Network-Based 3D Home Control System for Smart Home Environment", International Journal of Smart Home, vol. 10, no. 1, pp. 159-168, 2016. Available: 10.14257/ijsh.2016.10.1.16.

[23] F. Tian, X. Long and W. Liao, "Design of Smart home System Based on Basic Radio Frequency Wireless Sensor Network", International Journal of Online Engineering (iJOE), vol. 14, no. 04, p. 126, 2018. Available: 10.3991/ijoe.v14i04.8389.

[24] Y. Devrim and K. Pehlivanoğlu, "Design of a hybrid photovoltaicelectrolyzer-PEM fuel cell system for developing solar model", physica status solidi (c), vol. 12, no. 9-11, pp. 1256-1261, 2015. Available: $10.1002 /$ pssc.201510091.

[25] T. Li, H. Liu and D. Ding, "Predictive energy management of fuel cell supercapacitor hybrid construction equipment", Energy, vol. 149, pp. 718-729, 2018. Available: 10.1016/j.energy.2018.02.101.

[26] H. Mehrjerdi, "Off-grid solar powered charging station for electric and hydrogen vehicles including fuel cell and hydrogen storage", International Journal of Hydrogen Energy, vol. 44, no. 23, pp. 11574-11583, 2019. Available: 10.1016/j.ijhydene.2019.03.158.

[27] Y. Devrim and L. Bilir, "Performance investigation of a wind turbinesolar photovoltaic panels-fuel cell hybrid system installed at İncek region-Ankara, Turkey", Energy Conversion and Management, vol. 126, pp. 759-766, 2016. Available: 10.1016/j.enconman.2016.08.062.

\section{Nomenclature}

\begin{tabular}{|c|c|}
\hline $\mathrm{I}_{\mathrm{GEN}}$ & : PV generated current $(\mathrm{A})$ \\
\hline $\mathrm{I}_{\mathrm{DEM}}$ & : Load consumption current (A) \\
\hline $\mathrm{I}_{\mathrm{AP}}$ & : Appliance consumption current (A) \\
\hline $\mathrm{Q}_{\mathrm{P}}$ & : $\mathrm{H}_{2}$ produced amount (mol) \\
\hline $\mathrm{SOC}_{\mathrm{SC}}$ & : Supercapacitor state of charge \\
\hline $\mathrm{I}_{\mathrm{SC}}$ & : Supercapacitor current (A) \\
\hline $\mathrm{I}_{\mathrm{SCmax}}$ & : Supercapacitor maximum current (A) \\
\hline $\mathrm{P}_{\mathrm{st}}$ & : Tank pressure (bar) \\
\hline $\mathrm{T}_{\mathrm{st}}$ & : Tank temperature $\left({ }^{\circ} \mathrm{C}\right)$ \\
\hline $\mathrm{V}_{\mathrm{st}}$ & : Tank volume (1) \\
\hline $\mathrm{SOC}_{\mathrm{H} 2}$ & $: \mathrm{H}_{2}$ tank state of charge \\
\hline $\mathrm{SOC}_{\mathrm{H} 2 \mathrm{~min}}$ & $: \mathrm{H}_{2}$ tank state of charge min \\
\hline $\mathrm{Q}^{\mathrm{S}}$ & $: \mathrm{H}_{2}$ tank Stored amount (mol) \\
\hline $\mathrm{Q}_{\text {max }}^{\mathrm{S}}$ & : $\mathrm{H}_{2}$ tank maximum stored amount (mol) \\
\hline $\mathrm{N}_{\mathrm{EL}}$ & : Electrolyze cell numbers \\
\hline SOC $^{\mathrm{EST}}$ & : Estimated $\mathrm{H} 2$ tank state of charge \\
\hline $\mathrm{SOC}^{\mathrm{CH}}$ & : Estimated Supercapacitor state of charge \\
\hline $\mathrm{I}_{\mathrm{ST}}$ & : Estimated excess generated current (A) \\
\hline $\mathrm{I}_{\mathrm{SC}}{ }^{\mathrm{CH}}$ & : Supercapacitor charging current (A) \\
\hline $\mathrm{QH}_{\mathrm{H} \mathrm{V}}$ & : Vehicle fuel delivery (mol) \\
\hline$Q^{n}$ & : H2 needed amount (mol) \\
\hline $\mathrm{Q}_{\mathrm{VEH}}$ & : Vehicle fuel reserve (mol) \\
\hline $\mathrm{F}$ & : Faraday constant \\
\hline $\mathrm{SOC}_{\mathrm{H} 2 \max }$ & : $\mathrm{H}_{2}$ tank state of charge max \\
\hline
\end{tabular}

